\title{
MANAGEMENT AND RESEARCH WORKERS
}

$I^{N}$ $\mathrm{N}$ both industry and Government, a costly and dangerous trend is emerging - a trend towards a kind of management system the pattern of operation of which is incompatible with that required for highly oreative performance by scientific and engineering staff. It is a trend toward tighter budgetary controls and tighter organization of the work. It is brought about by the impact of greater competition and, even more, by faulty information concerning the relative effectiveness of various approaches to the reduction of cost and improved performance.

Prof. Rensis Likert suggests in the March issue of International Science and Technology that this is a dangerous trend because tighter controls, while appearing to provide desired results over a short-run period, may damage an organization over a longer span of time. As a counter-measure, he proposes a management system which enables scientists and engineers to function at their most creative level. This is a system which has evolved from an extensive programme of research by the Institute of Social Research of the University of Michigan. From the studies a number of observations concerning the performance of technical people has emerged.

When communications within the organization is frequent, scientists and engineers are likely to perform better. For example, patent applications by technical personnel are higher in such organizations, and employee evaluations of one another are also higher. Frequent communications with colleagues who think differently from one another also improve an organization's performance. Scientists who do communicate with one another, but who are not conscious of a need for competent colleagues-who maintain an independent frame of mind-tend to be better performers than those who are more dependent.

Scientists and engineers who see their administrative chief often perform better than those who do not. Their performance is better still when they can also set their own technical goals, or at least have some influence on their chief in setting those goals. Best performance is observed when the scientist has high self-determination combined with free access to someone in authority. The potentialities of younger subordinates are best developed by the supervisor who can maintain the difficult synthesis of close interest in the young man's work without domination of it. If the technical man's personal motivation is low and, if he is not deeply involved in his work. it is not advisable to allow more than moderate selfdetermination in his work. If his motivation is high, then full self-determination leads to best results.

These observations point to the important general conclusion that scientists and engineers are likely to be most creative when their supervision is such that they feel substantial freedom in their work-in selecting their problems and goals, in deciding on the approach to achievement, and in interpreting their data - and when they have frequent interaction with their superiors. These findings are valid for the administration of basic research, developmental research, and engineering. Such conclusions are often greeted with scepticism. To some it seems that the conclusions are obvious, needing no research to prove its validity. Many research directors argue that "my people do feel substantial freedom". Prof. Likert counters with examples to show that the true feelings of a manager's subordinates are probably quite different from what he believes them to be.

The other kind of scepticism involves a more traditional bias: if you allow too much freedom people will take advantage and the organization will suffer. Here studies have proved the reverse of this, but they have also shown that it takes time to institute such a programme. During a short period of, say, one year, the kind of programme proposed is likely to prove less productive than one that is oriented round tighter controls.

T. H. HAwKINS

\section{EDUCATION RESEARCH IN BRITAIN}

$I^{\mathrm{N}}$ $\mathrm{N}$ reply to a question in the House of Commons on April 19, the Minister of Education, Sir David Eccles, said that he had offered $£ 5,000$ a year for three years to the Educational Foundation for Visual Aids towards the running costs of its new experimental development unit; $£ 16,000$ over four years to the National Foundation for Educational Research for research into the relative merits of block release and day release; about $£ 12,000$ over three years to the University of Sheffield for research into the logical programming of mathematics syllabuses; and about $£ 9,500$ over four years to the University of Manchester for a sociological study in grammar schools. He expected that actual grants in 1962-63 for these projects would total about $£ 12,000$, and he was considering other applications.

Later, on April 19, in a debate on educational research opened by Mr. J. Boyden, the adequacy of the $£ 20,000$ which the Minister was making available for educational research was challenged. Starting with the comment in the Crowther Report that in a consistent programme of educational development almost the first step should be to review the provision for statistics and research, Mr. Boyden strongly urged more generous support for the educational research foundations. He also quoted Sir Howard Florey's appeal to the Parliamentary and Scientific Committee for greater support for university research. The universities needed more accommodation, more qualified and technical assistance and more adequate funds for research. In particular, evidence submitted to the Robbins Committee from the British Association for the Advancement of Science had been concerned with the relative lack of research facilities in sociology, social psychology and social anthropology. The lack of consistent policy in developing the social sciences within the university framework had very greatly added to the difficulties of building up a body of knowledge and methodology suitable for the study of the rapidly changing social conditions in Britain 